\title{
Hydrogen-Rich Gas for Clean Combustion in a Dual-Fuel Compression Ignition Engine
}

\author{
Horng-Wen Wu, Tzu-Ting Hsu, and Rong-Fang Horng
}

\begin{abstract}
Since burning of hydrogen emits fewer pollutants, it has been using as a clean alternative or auxiliary fuel of engines. This study is to develop a diesel/ hydrogen-rich gas dual fuel engine with methanol steam reforming method and design of EGR (Exhaust Gas Recirculation) system to investigate engine performance and exhausting pollutants. The measured items are composed of the gas pressure of cylinder, crank angle, diesel consumption rate, hydrogen consumption rate, air flow rate, and emissions $\left(\mathrm{HC}, \mathrm{CO}_{2}, \mathrm{NO}_{\mathrm{x}}\right.$, and Smoke), and the contents of hydrogen-rich gas. The authors analyze how the hydrogen-rich gas addition with EGR influences the combustion performance and emissions. The heat recovery reforming system can solve the storage and producing problem of hydrogen. Furthermore, the authors little altered the engine structure, and it is easy to put the energy saving and pollutants decrease into effect.
\end{abstract}

Index Terms - Clean combustion, diesel/hydrogen-rich gas engine, emission reduction, exhaust heat recovery, exhaust gas recirculation, methanol steam reforming.

\section{INTRODUCTION}

There are many applications of diesel engines in the worldwide such as automobile vehicle, power generation, power source of marine, and so on [1]. The global trend of environmental protection and energy has been depleting, which also represents energy costs will be higher than ever. In view of this, how to use energy more efficiently and to seek alternative fuels for fossil fuels will allow for no delay [2].

Hydrogen is regarded as one of promising alternative clean fuels for fossil fuels [3] and also to fill the need for sustainable energy development and environment protection [4]. There are three methods of hydrogen-rich gas: steam oxidation (POX), and auto-thermal reforming (ATR). This study uses methanol steam reforming reaction to produce hydrogen-rich gas. After methanol is mixed with water, it reacts with the reforming catalyst directly and produces hydrogen, carbon monoxide and carbon dioxide. This method is the most efficient and the most widely used by producing hydrogen; and the method is also the most productive for all

Manuscript received September 16, 2015; revised January 17, 2016. This work was supported by the Ministry of Science and Technology of Taiwan, ROC, NSC102-2221-E-006 -132-MY3.

Horng-Wen $\mathrm{Wu}$ is with the System and Naval Mechatronic Engineering Department, National Cheng Kung University, Tainan, Taiwan 701, R.O.C. (e-mail: z7708033@email.ncku.edu.tw).

Tzu-Ting Hsu was with the System and Naval Mechatronic Engineering Department, National Cheng Kung University, Tainan, Taiwan 701, R.O.C. (e-mail: mandarin800825@gmail.com).

Rong-Fang Horng is with the Mechanical Engineering Department, Kun Shan University, Tainan, Taiwan 710, R.O.C. (e-mail: hong.rf@msa.hinet.net). recombination reaction [5], [6]

Compared with common fuels, hydrogen has the characteristics of a long term renewable, recyclable and non-polluting fuel because it contains no carbon [7]-[9]. Furthermore, it had the characteristics of higher flame speed and larger diffusion speed benefit the energy efficiency and reduces emissions. The more rapid flame propagation and wider flammable range of hydrogen might lead to extended lean operating limits [10], and the engine could operate with a wide range of air/fuel ratio. The lower heating value of hydrogen is much higher $(120 \mathrm{MJ} / \mathrm{kg})$ than that of diesel fuel (42 MJ/kg). The auto-ignition temperature of hydrogen ( 858 $\mathrm{K})$ is also higher than diesel $(453 \mathrm{~K})$ [11], so hydrogen cannot be used in CI engine without spark plug. It makes hydrogen only fit for pilot complementary fuel for diesel engines.

Emonts et al. [12] set up a methanol reformer employing the catalytic burner to heat the reformer. They found that at low hydrogen yields, the methanol conversion efficiency could be up to $100 \%$. As the operating temperature increased from $260{ }^{\circ} \mathrm{C}$ to $280{ }^{\circ} \mathrm{C}$, the efficiency could be significantly improved. On the other hand, they found that the higher the temperature was, the higher the concentration of $\mathrm{CO}$ became. Lindström et al. [13] employed steam reforming combined with partial oxidation to establish a methanol reformer which reached reaction time from cold start up only about 300 seconds. When the reaction temperature reached $260{ }^{\circ} \mathrm{C}$, methanol conversion efficiency was about $90 \%$. Hohlein et al. [14] developed a methanol steam reformer system which was combined with catalytic burner and gas handling equipment at $240{ }^{\circ} \mathrm{C}, 260{ }^{\circ} \mathrm{C}$, and $280{ }^{\circ} \mathrm{C}$ of operating conditions. They found that the $\mathrm{CO}$ concentration of reformer outputs was related to the heating mode and the changed reformer temperature curve closely. Sun et al. [15] mixed ethanol into water and introduced new Ni- $\mathrm{Y}_{2} \mathrm{O}_{3}$ catalyst to reform. Their experimental results showed that hydrogen concentration of output was up to $67.6 \%$ and the fuel conversion efficiency was greater than $98 \%$ when temperature was at $350{ }^{\circ} \mathrm{C}$.

Moreover, Rakopoulos et al. [16] indicated that one of significant advantages that hydrogen might have as a fuel was its potential for increasing second law efficiency, due to fundamental differences in the mechanism of entropy generation during combustion with respect to the usual hydrocarbon-based fuels. Because of good combustion characteristics of hydrogen, Mohammadi et al. [17] tried to make hydrogen directly inject into cylinder of a single-cylinder test engine using a high-pressure gas injector. Their results indicated that direct injection of hydrogen prevented backfire, increased thermal efficiency and output power. Saravanan et al. [18] inducted hydrogen into a single-cylinder direct injection diesel engine at the intake port. 
They found that the brake thermal efficiency increased from $22.78 \%$ to $27.9 \%$ with $30 \%$ hydrogen enrichment when smoke and $\mathrm{NO}_{x}$ (only under lean burn condition) emissions decreased; conducting too much hydrogen at the intake port would cause engine knock.

Little research has been done on combustion characteristics and emissions of the combination of diesel engine with the heat recovery type of steam reforming system. Therefore, this study developed such a combination to produce hydrogenrich gas with the EGR system for low $\mathrm{NO}_{x}$ emission. The authors expected that the port addition of hydrogen in direct injection diesel engine has good combustion performance and low emissions. Moreover, the contents of hydrogen-rich gas, in-cylinder pressure, cyclic variations of indicated mean effective pressure (IMEP), heat release rate, brake thermal efficiency (BTE), brake specific fuel consumption (BSFC), and $\mathrm{CO}_{2}, \mathrm{NO}_{x}$, and smoke emissions are analyzed at different added hydrogen flow rates and EGR ratios.

\section{EXPERIMENTAL APPARATUS}

The experiments were conducted under various flow rates of hydrogen-rich gas and percentages of EGR for a fixed engine load and rotation speed. Fig. 1 shows a block diagram of the experimental apparatus used in this study, and Fig. 2 displays photographic view of the test setup. The engine used was a $624 \mathrm{~cm}^{3}$ single cylinder, water cooled, and four stroke diesel engine (Kubota RK-125). The main specifications of the engine are listed in Table I. The test setup includes hydrogen injection system, hydrogen cylinder, anti-explosion device, EGR system, and emissions ( $\mathrm{CO}, \mathrm{HC}, \mathrm{CO}_{2}, \mathrm{NO}_{x}$, and smoke) measuring equipment. Hydrogen-rich gas is supplied by a methanol reformer.

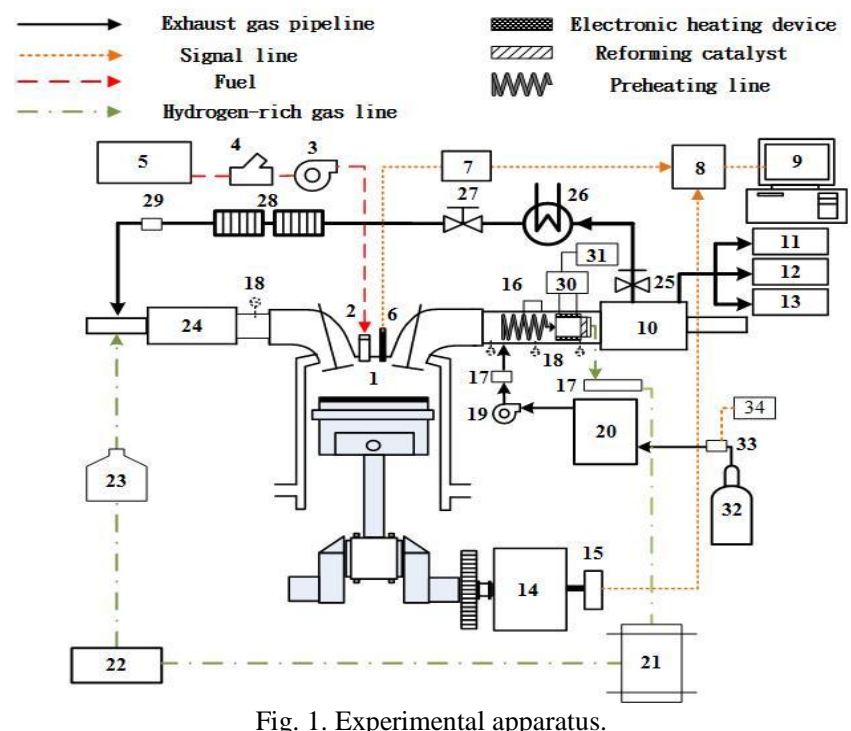

Description: 1: diesel engine; 2: Fuel injector; 3: Fuel pump; 4: Fuel filter; 5: Fuel tank; 6: Pressure sensor; 7: Signal amplifier; 9. Analog /digital signal converter; 10: Exhaust tank; 11: $\mathrm{NO}_{x}$ analyzer; $12: \mathrm{CO} / \mathrm{HC} / \mathrm{CO}_{2}$ analyzer; 13: Smoke analyzer; 14: Dynometer; 15: Crank angle detector; 16: Methanol steam reformer; 17: Flow meter; 18: Temperature sensor; 19: Fuel pump; 20: Methanol/water tank; 21: Seperator; 22: Hydrogen- rich gas control valve; 23: Flame trap; 24:Surge tank; 25: EGR valve; 26: Exhaust gas cooler; 27: EGR valve; 28: Carbon absorber; 29: EGR flow meter; 30: Power supply device; 31: PID temperature controller; 32: Carrier gas cylinder; 33.Carrier gas flow control valve; 34 : Carrier gas flow monitor.

For the EGR system, the exhaust gas, which was sent into the combustion chamber, had to be cooled by using the heat exchanger. The exhaust gas temperature was maintained around $28^{\circ} \mathrm{C} \pm 1^{\circ} \mathrm{C}$ by varying the flow rate of cooling water. The gas flow was then monitored by gas flow meter while EGR valve was adjusted to obtain the desired EGR ratio. The cooling gas was separated from the moisture by a separator before the cooling gas was conducted into the surge tank. The volume flow meters with Dwyer® Series DS-300 Standard valves are rated at $13.7 \mathrm{bar}$ and $93.3^{\circ} \mathrm{C}$. To measure the fuel volume flow rate, the authors used a $10 \mathrm{~mm}^{3}$ volumetric cylinder which was a bypass pipe of the fuel pipe. When the engine was under stable condition, the fuel pipe was switched to the $10 \mathrm{~mm}^{3}$ volumetric cylinder and the fuel consumption rate was therefore measured.

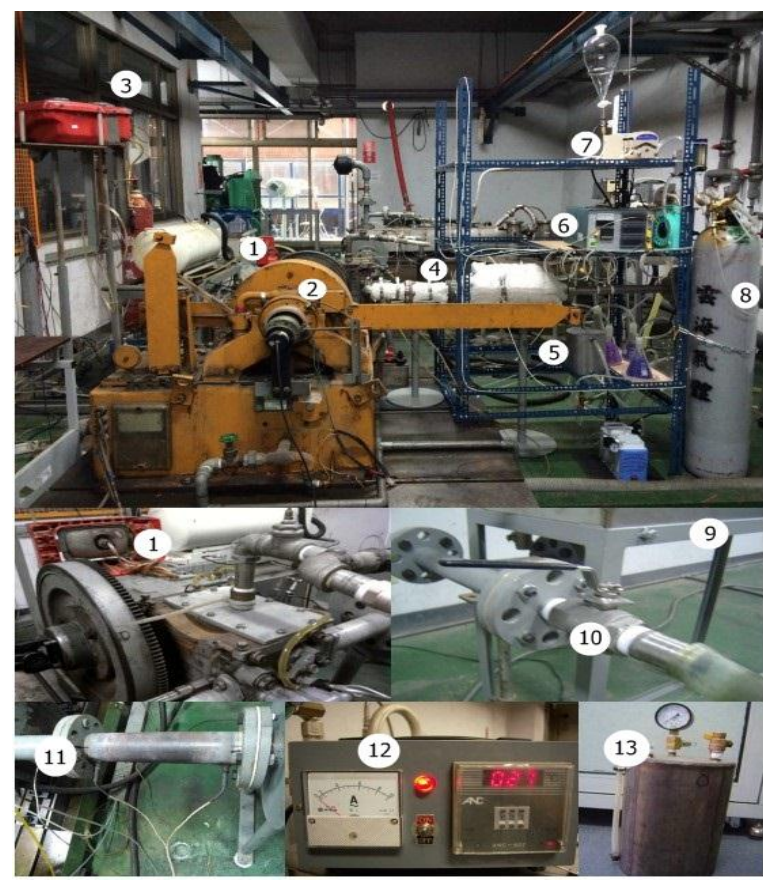

Fig. 2. Photographic view of the engine setup.

Description: 1: Diesel engine; 2: Dynamometer; 3: Fuel tank; 4: Reformer; 5: Cooler; 6: PID temperature controller; 7: Peristaltic pump; 8: Carrier gas cylinder; 9: Exhaust gas cooler; 10: EGR control valve; 11: Inlet heater; 12: Inlet heater temperature controller; 13: Flame trap.

A Kistler 6001 pressure transducer was used in conjunction with a charge amplifier, and Kistler 5011B to a data acquisition card was used to record the cylinder pressure. The crank degree signals required were obtained from a shaft encoder providing a resolution of 10 crank and an accuracy of \pm 0.05 o crank. Analog /digital signal converter NI PCI-6259 was connected with a computer quickly acquired and the cylinder gas pressure and the crank degree signals processed. Hydrogen flow was measured by using a thermal mass flow controller, GFC-37A-VAD. Its precision was $\pm 1.5 \%$ of full scale. The brake power arose about $1.5 \%$ when the hydrogen was injected into the chamber. BOSCH EAM3.011 was used 
to measure smoke emission, and HORIBA MEXA 584 was used to measure $\mathrm{CO} / \mathrm{HC} / \mathrm{CO}_{2}$ emissions. ACHO Physics CLD-60 was for measuring $\mathrm{NO}_{x}$ emission.

As indicated in Fig. 3, the reforming system includes methanol reformer, fuel supply system, heating and temperature control system, cooling system, gas sampling and analysis system, exhaust gas analysis system, and so on. The methanol reformer is made of shell tube in concentric cylinders composed of waste heat recovery zone and methanol steam reforming zone. The shell of reformer is covered with the electric heater which provides main heat source of a reforming reaction, and the electric heater is covered with asbestos for preventing heat loss. Through the inside of the reformer, a waste heat recovery tube with exhaust gas from a diesel engine passing through provides a secondary heat source of the reforming reaction heating the reformer to reach the required reforming reaction temperature.

TABLE I: THE SPECIFICATIONS OF THE ENGINE

\begin{tabular}{|l|l|}
\hline Bore $\times$ stroke & $94 \times 90 \mathrm{~mm}$ \\
\hline Displacement Volume & $624 \mathrm{~cm}^{3}$ \\
\hline Compression Ratio & 18 \\
\hline Rated output & $9.2 \mathrm{~kW}$ \\
\hline Rated speed & $2400 \mathrm{rpm}$ \\
\hline $\begin{array}{l}\text { Injection pressure of diesel } \\
\text { fuel injector }\end{array}$ & $21.57 \sim 22.56 \mathrm{MPa}$ \\
\hline Start of injection & $21.5^{\circ} \sim 23.5^{\circ}$ BTDC \\
\hline
\end{tabular}

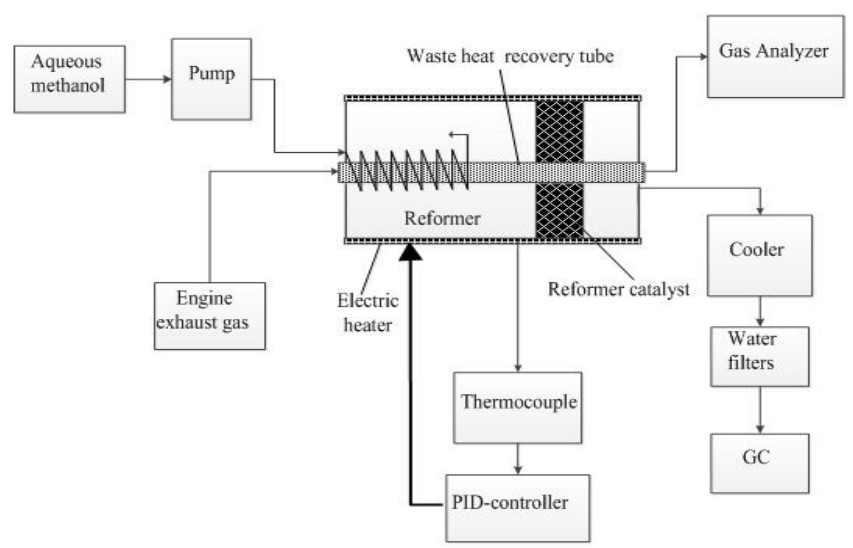

Fig. 3. Schematic of the methanol steam reforming system.

The required feeding rate of aqueous methanol is controlled by a peristaltic pump and a flow-meter. Fuel supply system includes fuel tank, peristaltic pump, flow meter, and feed preheat tube. The peristaltic pump is LongerPump C9ES-DG100M at 1-150 rpm with peristaltic pump head YZ1515X at $0.07-2200 \mathrm{ml} / \mathrm{min}$. The flow meter is AALBORG 022-13-ST within 0.550-5.78 ml/min. The PID controller provided a resolution of $1 \%$ crank and an accuracy of $2 \%$ crank. The electronic air flow meter is AALBORG CFC-17 within 0-10 1/min.

The cooling system includes a cooler body, submerged pumps, cryogenic tank, and anti-corrosion vacuum pump. The cooler is a parallel heat exchanger of $65 \mathrm{~mm}$ diameter and 200 $\mathrm{mm}$ length with internal copper pipes inside it. The gas sampling and analysis system includes airtight sampling bag and gas chromatography. After the gas mixture goes through the dry bottle, the gas is collected by gas sampling bag for gas composition analysis using gas chromatography. The gas chromatography is Agilient 6850 using thermal conductivity detector with error within $0.5 \%$ to measure the concentration of sampling gas, such as $\mathrm{H}_{2}, \mathrm{~N}_{2}, \mathrm{CO}$, and $\mathrm{CO}_{2}$.

\section{RESEARCH METHOD}

EGR is a $\mathrm{NO}_{x}$ reduction technique used in most gasoline and diesel engines. EGR works by re-circulating a portion of an engine's exhaust gas back to the engine cylinders. With higher specific heat, EGR can reduce the burning temperature in the cylinder for reducing $\mathrm{NO}_{x}$ emission. The definition of EGR ratio [11] in this study is given as

$$
\operatorname{EGR}(\%)=V_{\mathrm{EGR}} /\left(V_{\mathrm{air}}+V_{f}+V_{\mathrm{EGR}}\right)
$$

where $V_{\mathrm{EGR}}$ is the volume of engine's exhaust gas, $V_{\text {air }}$ the volume of the intake air, and $V_{f}$ the volume of fuel.

BSFC is the ratio of fuel mass flow rate to output power of an engine given by the following equation.

$$
\operatorname{BSFC}(\mathrm{g} / \mathrm{kW} \times \mathrm{h})=\frac{\dot{m}_{f}(\mathrm{~g} / \mathrm{h})}{B P(\mathrm{~kW})}
$$

where BP is the brake power and $\dot{m}_{f}$ is the mass flow rate of fuel $(\mathrm{g} / \mathrm{h})$; the fuel includes diesel, hydrogen, and carbon monoxide.

BTE is the ratio of work done by engine to the energy supplied to an engine given by the following equation.

$$
\mathrm{BTE}(\%)=\frac{\mathrm{BP}}{\mathrm{IER}} \times 100 \%
$$

where BP is the brake power measured by dynamometer and IER is input energy rate which means total energy rate inputted to the engine from combustion of fuel.

In this study, the IER means is determined as follows.

$$
\mathrm{IER}=\dot{m}_{d} \times h_{d}+\dot{m}_{\mathrm{H}_{2}} \times h_{\mathrm{H}_{2}}+\dot{m}_{\mathrm{CO}} \times h_{\mathrm{CO}}
$$

where $h_{d}$ is the lower heating value of diesel fuel $(42.5$ $\mathrm{MJ} / \mathrm{kg}), h_{\mathrm{H}_{2}}$ is the corresponding lower heating value of hydrogen $(120 \mathrm{MJ} / \mathrm{kg})$, and $h_{C O}$ is the corresponding lower heating value of carbon monoxide (1.18 MJ/kg).

Heat release rate reveals the combustion event and stages, but the actual formation is complicated. The heat release rate model [12] is used here by

$$
\frac{d Q}{d \theta}=\frac{1}{k-1}\left(k p \frac{d V}{d \theta}+V \frac{d p}{d \theta}\right)-\frac{p V}{(k-1)^{2}} \frac{d k}{d \theta}(J / C A)
$$

where $d Q / d \theta$ is the net heat-release-rate $(\mathrm{J} / \mathrm{CA}), \theta$ is the crank angle in degrees, and $V$ is the volume of the cylinder $\left(\mathrm{m}^{3}\right) . \quad k$ is the specific heat ratio calculated from the composition and temperature of in-cylinder gas, treated as a variable, and $d k / d \theta$ is thus obtained.

Because of many factors affecting combustion 
characteristics, even if engine operates under steady conditions, they are not same completely from cycle to cycle. If combustion variation is larger from cycle to cycle, then engine will operate unstably and produce burning incompletely to affect combustion characteristics of engine. The formula of cyclic variation written by its coefficient of variations (COV) [12] is as follows:

$$
\begin{aligned}
\operatorname{COV} & =\frac{\sigma}{\bar{Y}} \\
& =\frac{\sqrt{(N-1) \cdot \sum_{i=1}^{N}\left(Y_{i}-\bar{Y}\right)^{2}}}{\bar{Y}}
\end{aligned}
$$

where $\mathrm{COV}$ is the coefficient of variation, $\sigma$ is standard deviation, is the mean value, and $N$ is cycle numbers of sample; $N$ is equal to 100 in this study.

This study uses waste heat recovered from the exhaust gas to methanol reformer as its secondary heating source. Engine exhaust waste heat recovery ratio is defined as the ratio of consumption energy rate to total energy rate of engine exhaust gas. If the content of exhaust gas does not change after entering the reformer, the heat recovery ratio can be calculated by the difference between inlet and outlet temperature of reformer. The formula is defined as follows.

$$
\mathrm{WHR}(\%)=\frac{\dot{Q}_{\text {consumed }}}{\dot{Q}_{\text {exhaust }}} \times 100=\left(1-\frac{T_{\text {out }}}{T_{\text {in }}}\right) \times 100
$$

where $\dot{Q}_{\text {exhaust }}$ is the total energy rate of engine exhaust gas, and $\dot{Q}_{\text {consumed }}$ is the heat energy rate absorbed by methanol steam reforming.

\section{RESULTS AND DISCUSSION}

The operating parameter of steam reforming was input changed by flow rate of methanol aqueous solution. Changing the flow rate of methanol aqueous solution can control the production rate of hydrogen-rich gas. Other parameters of steam reformer was fixed at $\mathrm{S} / \mathrm{C}$ ratio 1.3 , reacting temperature $300^{\circ} \mathrm{C}$, and the flow rate of carrier gas is 40 c.c./min. Under the setting experimental condition, the contents of hydrogen- rich gas were listed in Table II. Hydrogen and carbon monoxide account for most of the contents up to more than $73.9 \%$, and they can assist engine combustion. Engine experiment was carried out by adjusting continuous hydrogen-rich gas with supplied flow rate of 7.6 1/min, $11.6 \mathrm{l} / \mathrm{min}$, and $15.7 \mathrm{l} / \mathrm{min}$ and 20 to $40 \%$ EGR ratio. The test engine is fixed at $60 \%$ load for various engine speeds. The results for $1800 \mathrm{rpm}$ and $45 \%$ load are discussed from Fig. 4 to Fig. 12.

The authors used exhaust gas introduction of reformer gas inlet temperature $\left(T_{\text {in }}\right)$ and exhaustion of reformer gas outlet temperature $\left(T_{\text {out }}\right)$ to get the waste heat recovery ratio (WHR) of engine exhaust gas, and the results are shown in Table III. The waste heat recovery ratio will be enhanced as the amount of the feed methanol aqueous solution is increased. Generally, the waste heat from exhaust gas accounts for some of the fuel input energy. If the waste heat cannot be used with an appropriate method, it will be discharged to the atmosphere directly. From the experimental results, the different ratios of methanol and water and reforming reaction temperatures will influence waste heat recovery ratio of reformer. For the overall experimental results, the highest rate of waste heat recovery can be up to $11.29 \%$, and the lowest rate of waste heat recovery is $10.4 \%$.

The hydrogen-rich gas conducted into the engine causes higher peak pressure. Fig. 4 shows the variations of in-cylinder pressure with hydrogen-rich gas flow rate for an EGR of $40 \%$, and the load at $60 \%$. The peak pressure with 7.6 $1 /$ min hydrogen-rich gas is $56.6 \mathrm{bar}$, with $11.6 \mathrm{l} / \mathrm{min}$ hydrogen is $57.7 \mathrm{bar}$, and with $15.7 \mathrm{l} / \mathrm{min}$ hydrogen is $62.4 \mathrm{bar}$. The fast flame speed causes the advance in peak pressure for higher hydrogen flow rate compared with the lower one. Hydrogen-rich gas addition generates an increase in the peak heat release rate. This is because of the longer ignition delay, and a greater amount of diesel fuel is thus burned during the premixed combustion phase. Similar to the in-cylinder pressure, the higher hydrogen-rich gas flow rate causes higher peak heat release rate as displayed in Fig. 5. In this study, the coefficient of variation $(\mathrm{COV})$ of indicated mean effective pressure (IMEP) with hydrogen flow rate and the EGR ratio can determine the stability of engine combustion. Problems often occur when COV of IMEP exceeds about $10 \%$. Fig. 6 demonstrated that higher EGR ratio would cause the more variation of COV. Fortunately, the COV of IMEP values for all conditions are lower than $10 \%$ (from $1.2 \%$ to $2.8 \%$ ), and these are small cyclic variations. From Fig. 6, COV of IMEP with EGR is obviously higher; this is because EGR causes poor combustion to increase the post-combustion, and thus leads to more unstable engine operation. However, these are still small cyclic variations. As a result, the addition of hydrogen-rich gas and EGR would not generate the unstable combustion.

TABLE II: THE CONTENTS OF HYDROGEN-RICH GAS

\begin{tabular}{|c|c|c|c|c|}
\hline Experimental run & $\mathrm{H}_{2}(\%)$ & $\mathrm{N}_{2}(\%)$ & $\mathrm{CO}_{2}(\%)$ & $\mathrm{CO}(\%)$ \\
\hline $\begin{array}{c}\text { T300, S/C } 1.3, \\
6.5 \mathrm{~g} / \mathrm{min}\end{array}$ & 70 & 0.521 & 21.6 & 3.879 \\
\hline $\begin{array}{c}\text { T300, S/C } 1.3, \\
10 \mathrm{~g} / \mathrm{min}\end{array}$ & 70.6 & 0.339 & 22.3 & 2.761 \\
\hline $\begin{array}{c}\text { T300, S/C } 1.3, \\
13.5 \mathrm{~g} / \mathrm{min}\end{array}$ & 71.1 & 0.253 & 21.8 & 2.847 \\
\hline $\begin{array}{c}\text { Experimental run } \\
\text { T300, S/C } 1.3, \\
6.5 \mathrm{~g} / \mathrm{min}\end{array}$ & \multicolumn{2}{|c|}{7.6} & \multicolumn{2}{|c|}{$\begin{array}{c}\text { Hethandrogen-rich conversion } \\
\text { production rate (L/min) }\end{array}$} \\
\hline $\begin{array}{c}\text { T300, S/C } 1.3, \\
10 \mathrm{~g} / \mathrm{min}\end{array}$ & \multicolumn{2}{|c|}{11.6} & \multicolumn{2}{|c|}{63.95} \\
\hline $\begin{array}{c}\text { T300, S/C } 1.3, \\
13.5 \mathrm{~g} / \mathrm{min}\end{array}$ & \multicolumn{2}{|c|}{15.7} & \multicolumn{2}{|c|}{62.42} \\
\hline
\end{tabular}

TABLE III: THE WASTE HEAT RECOVERY WITH VARIOUS FLOW RATE OF

\begin{tabular}{|} 
METHANOL AQUEOUS SOLUTION \\
\begin{tabular}{|c|c|c|c|}
\hline $\begin{array}{c}\text { Experimental } \\
\text { run }\end{array}$ & T_in (k) & T_out (k) & WHR $(\%)$ \\
\hline $\begin{array}{c}\text { T300, S/C } 1.3, \\
6.5 \mathrm{~g} / \mathrm{min}\end{array}$ & 538 & 482 & 10.40 \\
\hline $\begin{array}{c}\text { T300, S/C } 1.3, \\
10 \mathrm{~g} / \mathrm{min}\end{array}$ & 541 & 481 & 11.09 \\
\hline $\begin{array}{c}\text { T300, S/C } 1.3, \\
13.5 \mathrm{~g} / \mathrm{min}\end{array}$ & 540 & 479 & 11.29 \\
\hline
\end{tabular}
\end{tabular}




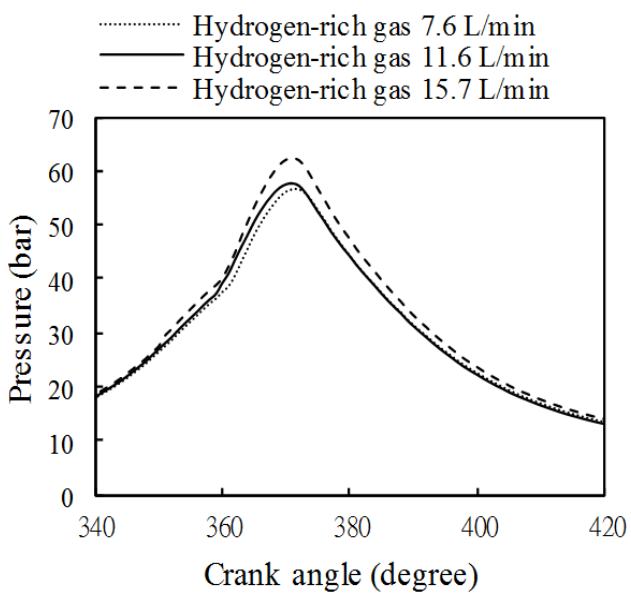

Fig. 4. Variations of in-cylinder pressure with hydrogen flow rate for the load at $60 \%$ and the EGR ratio of $40 \%$.

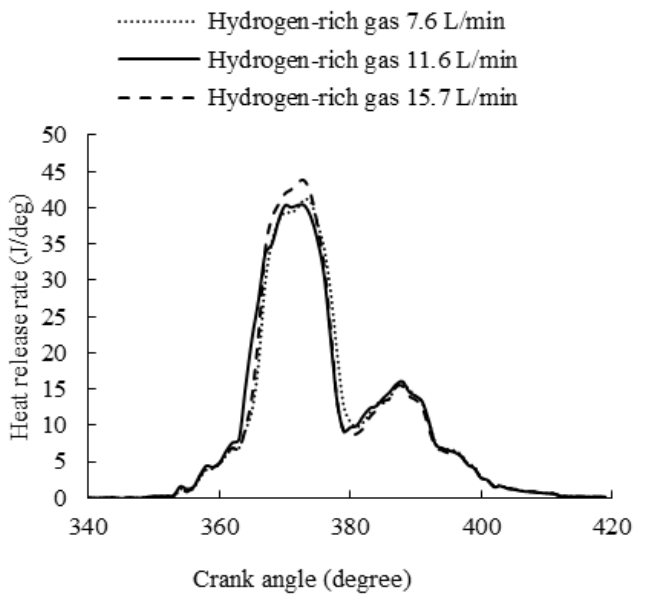

Fig. 5. Variations of heat release rate at different EGR ratios.

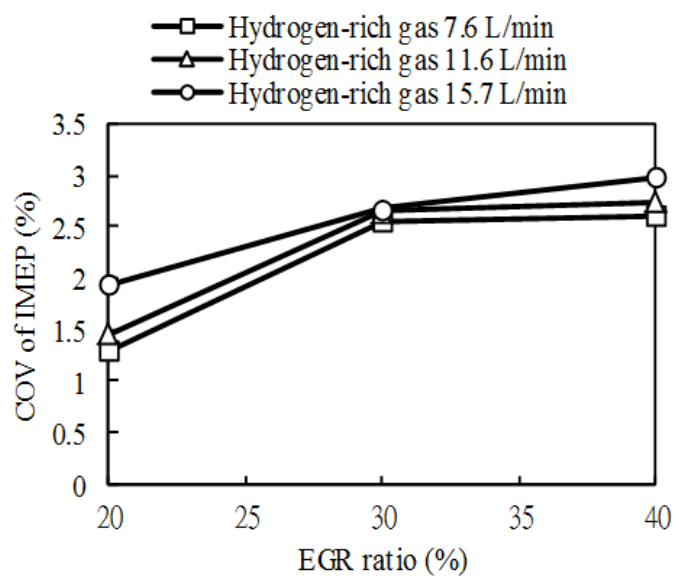

Fig. 6. Variations of COV of IMEP at different EGR ratios.

Fig. 7 indicates that the brake thermal efficiency alters significantly at low EGR ratio, but adding hydrogen-rich gas makes BTE become insignificant as EGR ratio increases. However, the fuel consumption would decrease at higher hydrogen-rich gas flow rate as shown in Fig. 7. There are two reasons to for this phenomenon. First, the $\mathrm{CO}_{2}$ concentration increased as the amount of re-circulated exhaust gas additive increased. A certain volume of intake air was substituted by $\mathrm{CO}_{2}$, so it would reduce the combustion temperature and cause some poor combustion. The original output power would be affected by incomplete combustion. For the sake to get the same power, the engine must consume more fuel. Second, hydrogen helps chemical reactions of diesel in the cylinder enhance combustion. For better effect of energy saving, the amount of hydrogen-rich gas additive and EGR ratio should take a trade-off.

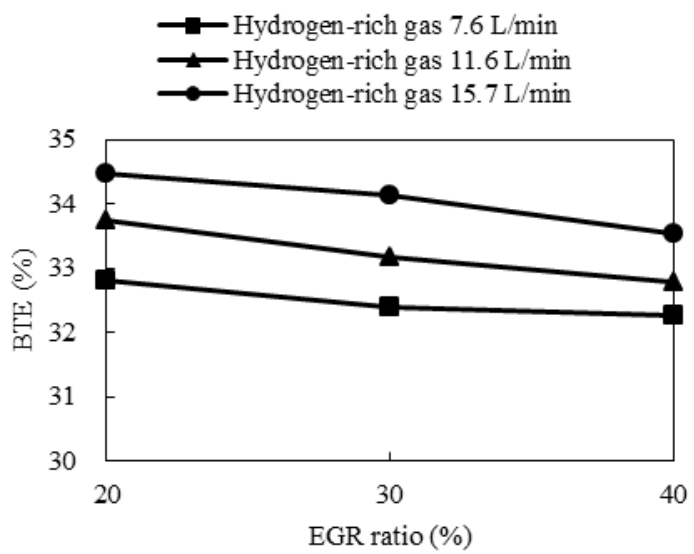

Fig. 7. Variations of BTE at different EGR ratios.

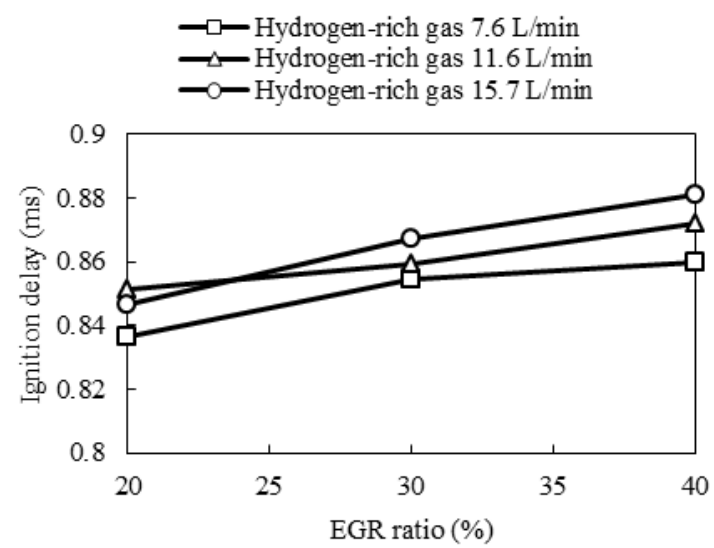

Fig. 8. Variations of ignition delay at different EGR ratios.

Fig. 8 displays the variation of ignition delay. The increase in ignition delay for EGR condition is as a result of decreasing of heating value of fuel by EGR and the increase in ignition delay for adding hydrogen-rich gas with diesel is due to adding hydrogen will decrease the cetane number of the mixing fuel and lower compression temperature caused by diluted oxygen, so the ignition delay increases. Fig. 9 shows that $\mathrm{CO}_{2}$ concentration decreases with an increase in hydrogen-rich gas addition because of more complete combustion. When the EGR ratio increases, the $\mathrm{CO}_{2}$ concentration becomes higher since $\mathrm{CO}_{2}$ is present in exhaust gas with EGR. Fig. 10 indicates that $\mathrm{HC}$ concentration rises owing to less oxygen in air and more hydrogen in fuel when hydrogen addition increases. The more the EGR ratio is, and the higher the $\mathrm{HC}$ concentration becomes since oxygen concentration is lower to burn more incompletely. Fig. 11 displays that $\mathrm{NO}_{\mathrm{X}}$ concentration increases with an increase in hydrogen-rich gas addition because of higher combustion temperature. When the EGR ratio increases, the $\mathrm{NO}_{\mathrm{X}}$ concentration becomes lower compared with original baseline diesel engine. This is since the re-circulated exhaust gas dilutes the intake gas mixture to lower the combustion temperature. Fig. 12 shows that smoke concentration decreases owing to fewer carbons in fuel as hydrogen-rich gas addition is raised. The smoke concentration increases with an increase in the EGR ratio since oxygen concentration is lower when the re-circulated exhaust gas is added more. After being 
validated with previous research work [7], [8], this paper has the same trend of smoke and $\mathrm{NO}_{x}$ with their results, but the change magnitude is different due to different amounts of hydrogen.

Moreover, with EGR ratio $40 \%$ and hydrogen flow rate $15.71 / \mathrm{min}$, the $\mathrm{CO}, \mathrm{CO}_{2}, \mathrm{NO}_{x}$, and smoke give better results; this is because when hydrogen into the cylinder is at high flow rate, the in-cylinder temperature is higher and the hydrogen burns quickly. A reduction in $\mathrm{NO}_{x}$ emissions is observed due to hydrogen addition at higher EGR ratios.

For the innate design of engine, too much hydrogen additive may cause cylinder temperature to become very high. The overheat exhaust would cause the cylinder broken and the temperature of cooling water to climb to boiling point.

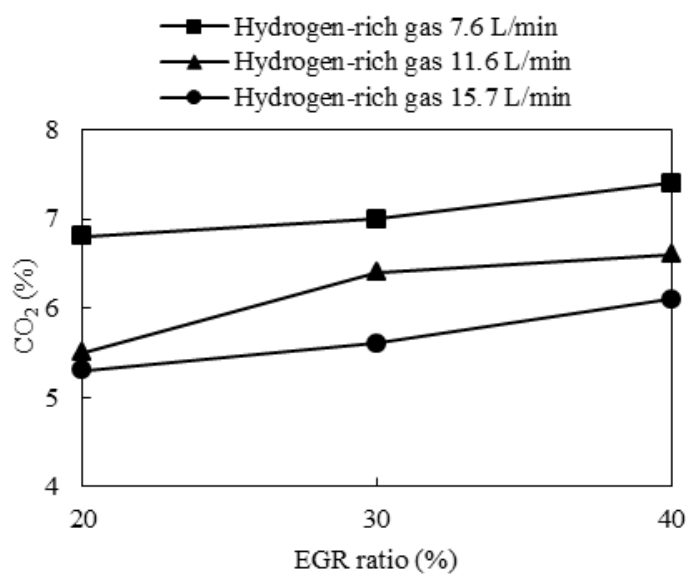

Fig. 9. Variations of $\mathrm{CO}_{2}$ at different EGR ratios.

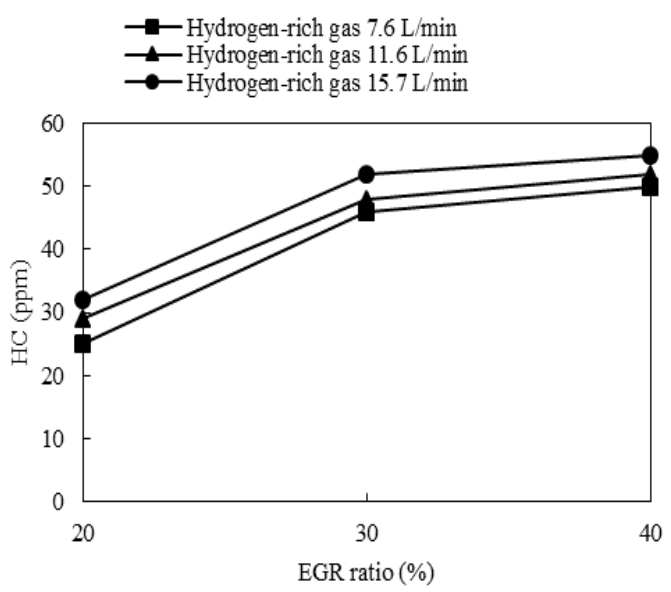

Fig. 10. Variations of $\mathrm{HC}$ at different EGR ratios.

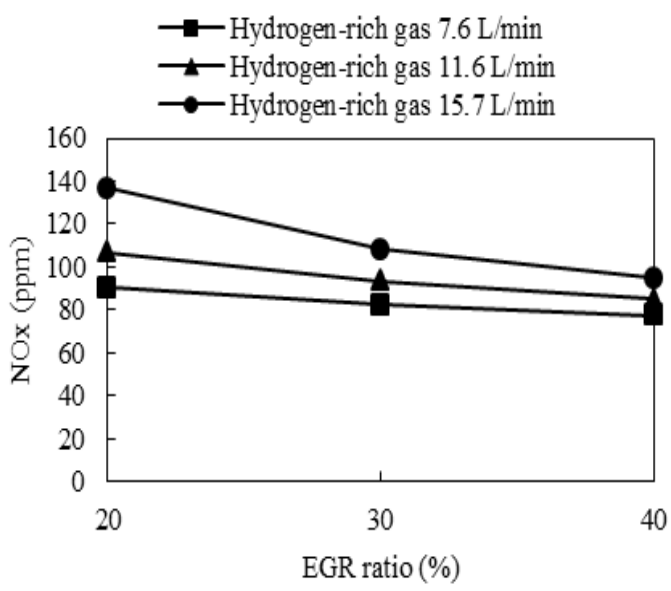

Fig. 11. Variations of $\mathrm{NO}_{x}$ at different EGR ratios.

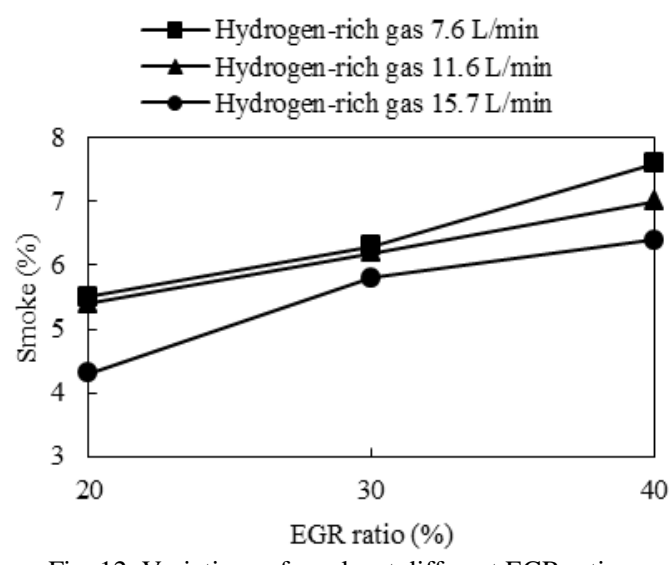

Fig. 12. Variations of smoke at different EGR ratios.

For these reasons, this study only choose hydrogen-rich gas flow rate at $15.7 \mathrm{l} / \mathrm{min}$ to add into the manifold. As a result, the condition makes good combustion, and thus reduces the emissions.

\section{CONCLUSION}

After having finished a diesel/ hydrogen-rich gas dual fuel engine with methanol steam reforming method and EGR system, this study investigated the engine combustion performance and emissions at different added hydrogen-rich gas flow rates and EGR ratios. Employing port-induced hydrogen and EGR system can increase engine efficiency with a greater reduction in emissions. The integration of methanol steam reforming system and diesel engine effectively can recover the waste heat energy from exhaust gas. The combination of reformer and engine also solves the storage problem of hydrogen. If hydrogen has much safer source, the application of hydrogen energy may be proved to commonly use.

\section{ACKNOWLEDGMENT}

The authors gratefully acknowledge the support of the Ministry of Science and Technology of Taiwan, ROC, NSC102-2221-E-006-132-MY3.

\section{REFERENCES}

[1] S. J. Heywood, Internal Combustion Engine Fundamentals, New York, U.S.A: McGraw- Hill Book Company, 1988, ch. 1.

[2] A. Demirbas, Biohydrogen: For Future Engine Fuel Demands, New York: Springer Dordrecht Heidelberg, 2009, ch. 1.

[3] A. Fuhs, Hybrid Vehicles and the Future of Personal Transportation, Abingdon, Oxford: Taylor \& Francis Group, LLC, 2009, p. 93.

[4] S. Verhels, "Recent progress in the use of hydrogen as a fuel for internal combustion engines," International Journal of Hydrogen Energy, vol. 39, pp. 1071-1085, Jan. 2014.

[5] J. S. Han, I. S. Kim, and K. S. Choi, "Purifier-integrated methanol reformer for fuel cell vehicles," J. Power Sources, vol. 86, pp. 223-227, Mar. 2000.

[6] B. Emonts, J. B. Hansen, H. Schmidt, T. Grube, B. Höhlein, R. Peters, and A. Tschauder, "Fuel cell drive system with hydrogen generation in test," J. Power Sources, vol. 86, pp. 228-236, March 2000.

[7] F. H. Ma, Y. Wang, H. Q. Liu, Y. Li, J. J. Wang, and S. F. Ding, "Effects of hydrogen addition on cycle-by-cycle variation in a lean burn natural gas spark-ignition engine," International Journal of Hydrogen Energy, vol. 33, pp. 391-402, Jan. 2008.

[8] N. Saravanan, G. Nagarajan, C. Dhanasekaran, and K. M. Kalaiselvan, "Experimental investigation of hydrogen port fuel injection in Di diesel engine," International Journal of Hydrogen Energy, vol. 32, pp. 4071-4080, Nov. 2007. 
[9] E. Tomita, N. Kawahara, Z. Piao, and S. Fujita, "Hydrogen combustion and exhaust emissions ignited with diesel oil in a dual fuel engine," SAE Tech. Paper 1, p. 3503. Sep. 2001.

[10] C. M. White, R. R. Steeper, and A. E. Lutz, "The hydrogen-fueled internal combustion engine: A technical review," International Journal of Hydrogen Energy, vol. 31, pp. 1292-305, Aug. 2006.

[11] G. H. Abd-Alla, "Using exhaust gas recirculation in internal combustion engines: A review," Energ. Convers Manage, vol. 43, pp. 1027-1042, May 2002.

[12] B. Emonts, J. B. Hansen, S. L. Jørgensen, B. Höhlein, and R. Peters, "Compact methanol reformer test for fuel-cell powered light-duty vehicles," J. Power Sources, vol. 71, pp. 288-293, March 1998.

[13] B. Linddström and L. J. Pettersson, "Development of a methanol fuelled reformer for fuel cell application," J. Power Sources, vol. 118, pp. 71-78, May 2003.

[14] B. Hohlein, M. Boe, H. J. Bogild, P. Brockerhoff, G. Colsman, and B Emonts, "Hydrogen from methanol for fuel cells in mobile system :development of a compact reformer," J. Power Sources, vol. 61, pp. 143-147, July-Aug. 1996

[15] J. Sun, D. Luo, P. Xiao, L. Jigang, and S. Yu, "High yield hydrogen production from low $\mathrm{CO}$ selectivity ethanol steam reforming over modified $\mathrm{Ni}-\mathrm{Y}_{2} \mathrm{O}_{3}$ catalysts at low temperature for fuel cell application," J. Power Sources, vol. 184, pp. 385-391, Oct. 2008.

[16] C. D. Rakopoulos, M. A. Scotta, D. C. Kyritsisa, and E. G. Giakoumis, "Availability analysis of hydrogen/natural gas blends combustion in internal combustion engines," Energy, vol. 33, pp. 2043-2056, Feb. 2008.

[17] A. Mohammadi, M. Shioji, Y. Nakai, W. Ishikura, and E. Tabo, "Performance and combustion characteristics of a direct injection $\mathrm{S}$ hydrogen engine," International Journal of Hydrogen Energy, vol. 32, pp. 296-304, Feb. 2007.

[18] N. Saravanan and G. Nagarajan, "Experimental investigation on a Di dual fuel engine with hydrogen injection," International Journal of Energy Research, vol. 33, pp. 295-308, March 2009.

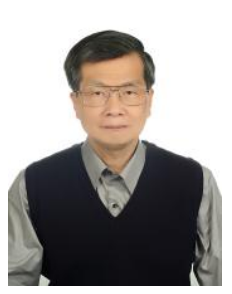

Horng-Wen Wu was born in Changhua county, Taiwan, and his birthdate is Feb. 01, 1957. He earned his BS degree in mechanical engineering from National Chung Hsing University, Taichung, Taiwan, in 1979, MS and $\mathrm{PhD}$ degrees in mechanical engineering from National Cheng Kung University, Tainan, Taiwan, in 1981 and in 1988, respectively.

$\mathrm{He}$ is a professor with National Cheng Kung University, Tainan, Taiwan, Taiwan, from 1998 until now; he was a visiting professor at Michigan State University from 2001 to 2002; an associate professor with National Cheng Kung University, Tainan, Taiwan, Taiwan, from 1989 to 1998; an instructor with National Cheng Kung University, Tainan, Taiwan, Taiwan, from 1988 to 1989; assistant with National Cheng Kung University, Tainan, Taiwan, from 1983 to 1984; and he was a second lieutenant, in army at design department of 202 armory, Taiwan, from 1981 to 1982 . His research interests include internal combustion engines, fuel cell, electronic device cooling related to performance enhancement, air pollution control and heat transfer enhancement. He published over 73 research papers including 51 SCI and 10 EI international journal publications in International Journal of Heat and Mass Transfer, International Journal of Thermal Sciences, Energy, Journal of Heat Transfer-Transactions of the ASME, Energy Conversion and Management, International Journal of Hydrogen Energy, Journal of Power Sources, and so on.

Prof. Wu received the excellent young engineer, from Association of Naval Architects and Marine Engineers, R.O.C., in 1991, awards of excellent work on research project from Excecutive Yuan, in 1996, award grants and leader grants of general research project from National Science Council or the Ministry of Science and Technology of R.O.C., in 1980, 1997, 1998, and 2002 2015, and awards of excellent work for technology transfer and collaboration between industry and university from National Chung Hsing University in 2010. He received award of excellent research professor of System and Naval Mechatronic Engineering Department, National Cheng Kung University in 2011, 2013, 2014, and 2015. He has obtained seven pieces of patents related to underwater power, PEM fuel cell, fuel preheating system, purification of particle dust, and treatment of burned gas.

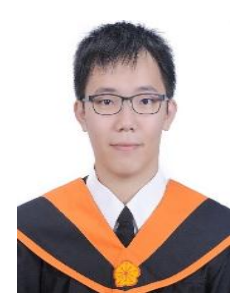

Tzu-Ting Hsu was born in Taichung, Taiwan, on August 25, 1991. The educational background of Mr. Hsu is based on marine engineering and aeronautics and astronautics engineering. He has double majors of the bachelor degree in the above two departments in 2013. After finishing the bachelor degree, he applies for graduate school in the Department of System and Naval Mechatronic Engineering. Finally, Mr. Hsu gains the master degree of system and naval mechatronic engineering in NCKU, Taiwan, Tainan, in 2015. His major field of study is the internal combustion of diesel engine and the application hydrogen energy.

He was the class assistant of computer programming design and the principles of experimental design for naval architecture. He started serving in army from December 2015, and was working as a research substitute service of a mechanical engineer in the Feng Hsin Steel Corporation, Taichung, Taiwan.

Mr. Hsu has earned the best session paper award in the International Forum on Systems and Mechatronics 2014 with the topics of "Performance and emissions of a diesel/ hydrogen dual fuel turbocharged Engine operated with exhaust gas recirculation."

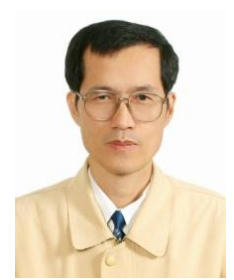

Rong-Fang Horng was born in Tainan, Taiwan on October 30, 1955. He received his $\mathrm{PhD}$ degree from the Department of Mechanical Engineering, National Cheng Kung University, Tainan, Taiwan, in 1994; the master degree from the Department of Mechanical Engineering, National Cheng Kung University, Tainan, Taiwan in 1982, and received his bachelor degree in the Department of Mechanical Engineering, National Cheng Kung University, Tainan, Taiwan, 1980. The major fields of study include thermal science and engineering; combustion characteristics of lean burn SI engine fueled with alcohols blended gasoline fuel; study of combustion and emissions of small engine with air-assisted in-cylinder fuel injection with in cylinder gas sampling system and high speed camera for wall impingement observation of air-assisted fuel injection.

$\mathrm{He}$ is a professor (from 2005 till now), associate professor (from 2000 to 2005) and assistant professor (from 1998 to 2000) of the Department of Mechanical Engineering, Kun-Shan University, Tainan, Taiwan, respectively. He ever served in the Mechanical Industrial Research Laboratory (MIRL), Industrial Technology Research Institute (ITRI) as an associate researcher (from 1983 to 1987) and researcher (from 1987 to 1998 ) respectively in Hsinchu, Taiwan. His present and previous research fields include: 1). Internal combustion engine: fuel economy, exhaust emission reduction, performance improvement; 2). Hydrogen production by reforming of hydrocarbon fuels, bio-alcohols, bio-gas, etc. The reformate gases are applied in engines, fuel cells, etc. 3). Reduction of green-house gases: reforming of carbon dioxide, methane, which is applied to reforming of natural gas, land filled gas, and unconventional natural gas. His publications contain 46 journal papers (SCI, EI and others), over 120 conference papers, over 50 patents.

Professor Horng was the recipient of Outstanding Presentation on SETC in Japan, Lamont Eltinge, 1991; received the Award of Outstanding Researcher for Science and Technology, by Executive Yuan of ROC (Taiwan), 1988, membership of Phitauphi of ROC (Taiwan), 1994, membership of Taiwan Association for Hydrogen Energy and Fuel Cell (THEFC), since 2005, membership of Taiwan Energy Association, since 2013, he is one of the organizing committee and technical committee for SETC 2013 19th Small Engine Technology Conference of SAE International Taipei Section (2013) 